\title{
MAXIMUM POWER POINT TRACKING OF PHOTOVOLTAIC SYSTEMS WITH GRID CONNECTED INVERTER BY USING BACKSTEPPING CONTROLLER
}

Harshith K N1, V.M Parthasarathy ${ }^{2}$

E-Mail Id: harshithkn31@gmail.com,vm parthasar athy08@g mail.com

Department of Electrical and Electronics Engineering, NITTE Meenakshi Institute Technology

Bengaluru, India

Abstract- This Photovoltaic system to track the maximum power point. The Backstepping controller is used to designed for applied the boost dc converter to improve its performances and to achieve optimal Photovoltaic array output voltage. The Vref is to be provided perturb and observe method. This Lyapunov function is controlled based on the local stability of the sys.tem. grid-connected inverters is used for photovoltaic system to performance modeling and for continuous monitoring of inverter performance during system operation. Hence to prove the maximum power extraction of the system is guaranty. The backstepping method is to be sustain the stability of the converter in wide range of the variations in temperature, radiation.. etc. Simulations used to demonstrate the efficiency in the presence of the environmental perturbations.

Keywords: Backstepping, Boost converter, Photovoltaic system, maximum power point, PV grid connected system, Lyapunov stability.

\section{INTRODUCTION}

Energy conservation is as important as enhancing the energy generation capacity. Large amounts of Energy are wasted every day due to negligence, and lack of appreciation of the seriousness of the impending energy crisis by the general public. As India is developing rapidly the fossil fuel reserve is being consumed at a very high rate. Serious effort needs to be put in to educate the populace so that the peak and average energy demand can be significantly reduced by adopting appropriate measures for energy conservation. In existing system perturb and observe $(\mathrm{P} \& \mathrm{O})$, incremental conductance method has been implemented .Grid voltage control scheme based on neuro-fuzzy inference based control, neutral point clamped scheme has been implemented. Conventional converter has been implemented in existing system. It evolves the conventional P\&O method to track the GMPP. Although, it has a good performance under PSC, it requires to measure the voltage of each module, and that may increase the total cost for large scale PV systems and increase the implementation complexity. This method, limits the search area for GMPP and yields suitable results, but needs high sampling number, which increases the complexity. . In this hybrid technique, $\mathrm{P} \& \mathrm{O}$ is performed under uniform insolation conditions, when PSC occurs the PSO is employed. In addition, PSO search area is reduced by using window based search, to reduce the power oscillations and convergence time. Solar module is a series or parallel configuration of PV cells. Series configuration of cells is used to generate power at a higher potential with current remaining unchanged, whereas the parallel configuration will generate higher current while the potential remains unchanged The drawback of this method is that if the partial shade detection fails, algorithm will never shift to the PSO. For this reason P\&O algorithm can be trapped at the local maximum. We can use to Improved dynamics ,Robustness, Reduction of operating switching frequency.more default in the High distortion, THD value high,Time computation,high Complexity. The output voltage using the MPPT based on the backstepping controller is more smooth and it contained lesser oscillations. The controller is more robust and fast in nature.

\section{MODELLING AND CONTROL OF PV SYSTEM}

It is simple, accurate and very easy to implement. If in duty cycle, the step changes is large, then it has high tracking speed. Step change in duty cycle is small, it gives high accuracy result. Solar radiation is converted into electrical energy by photo-voltaic solar cells. Solar cells are made up of semiconductor material. The cell is typically a "pn" junction. Lots of "free" charge carriers are available in Semiconductor material. Exposure of the semiconductor material of the solar cell to the photons constituting the sunlight will transfer sufficient energy to the electrons which will enable them to jump out of the valence band into the conduction band. Consequently, there will be a lack of an electron in the valence band which is termed as a hole. Solar module is a series or parallel configuration of PV cells. Series configuration of cells is used to generate power at a higher potential with current remaining unchanged, whereas the parallel configuration will generate higher current while the potential remains unchanged.

DOI Number: https://doi.org/10.30780/IJTRS.V04.I07.001

pg. 1

www.ijtrs.com

www.ijtrs.org

Paper Id: IJTRS-V4-I5-030

Volume IV Issue VII, July 2019 


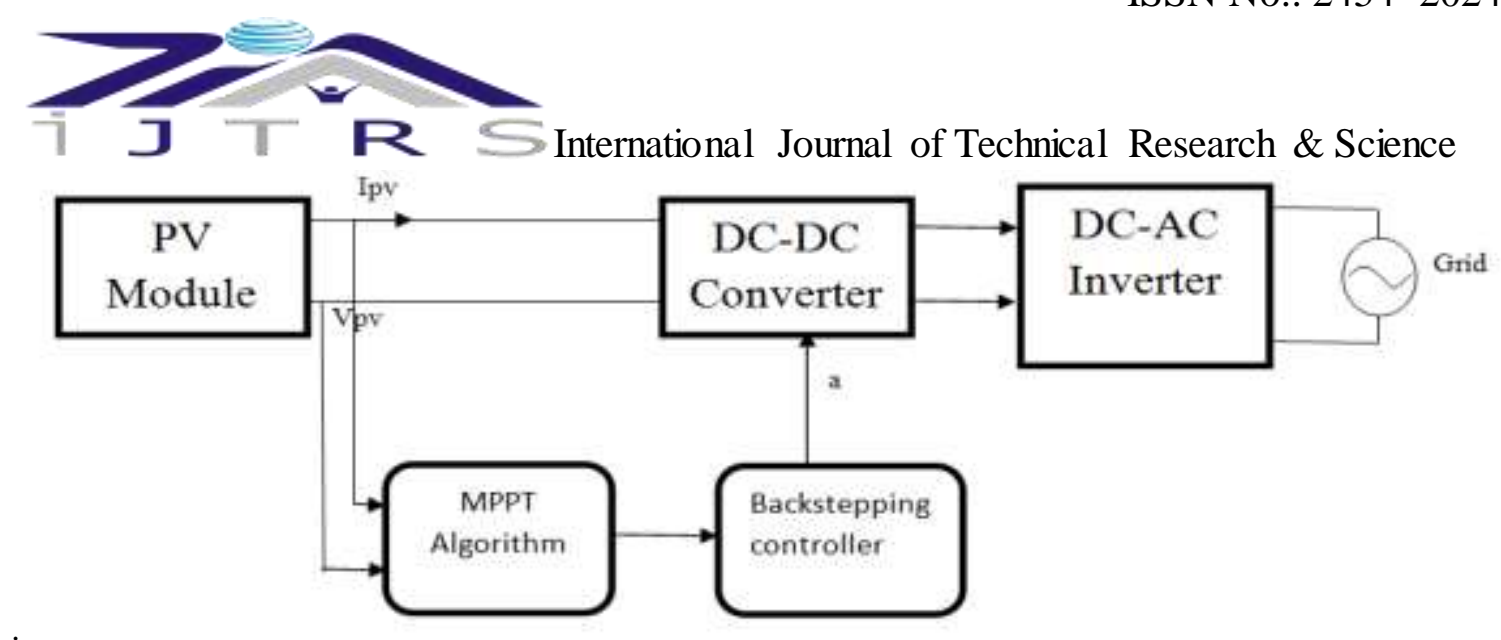

Fig. 2.1 The complete PV System with the MPPT Control Unit

\subsection{Modeling of the PV Module}

PV arrays square measure a singular supply of power generation therein they're affected by the location of the sun, shading, and temperature changes It is simple, accurate and very easy to implement. If in duty cycle, the step changes is large, then it has high tracking speed. Step change in duty cycle is small, it gives high accuracy result An electrical device which is used to generate electricity directly from solar radiation is known as solar cell. The "p" side of a "pn" junction contains excess of holes while the " $n$ " side contains an excess of electrons. It is simple, accurate and very easy to implement. If in duty cycle, the step change is large, then it has high tracking speed. Step change in duty cycle is small, it gives high accuracy result Movement of electrons from the " $n$ " side to "p" side will create a barrier potential at the junction.

Solar module is a series or parallel configuration of PV cells. Series configuration of cells is used to generate power at a higher potential with current remaining unchanged, whereas the parallel configuration will generate higher current while the potential remains unchanged. Appropriate configuration needs to be chosen depending on the desired output This model is a simplified version of the two-diode model presented in [10]. The circuit diagram of the solar cell is shown in fig. 2.2.

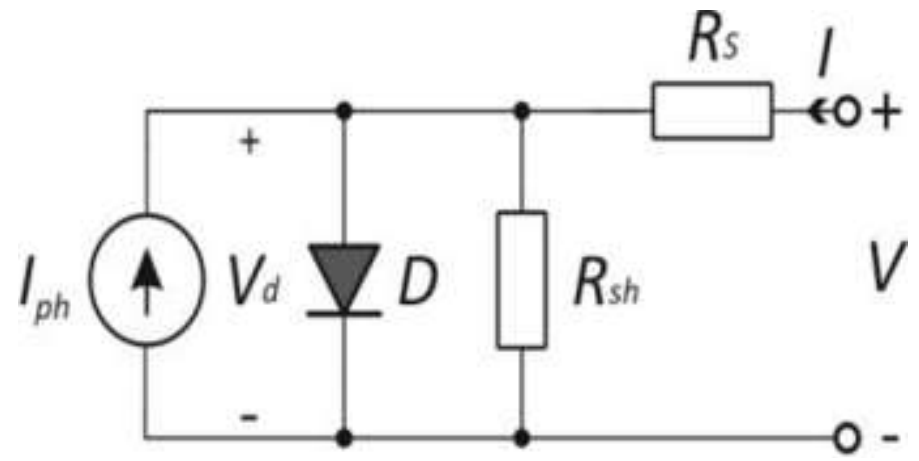

Fig. 2.2 Equivalent Circuit of One-Diode Model of the PV Cell

Table-2.1 PV Specification

\begin{tabular}{|c|c|}
\hline Parameters & Values \\
\hline Power in watts & 66.27 \\
Voltage in volts for MPP & 15.82 \\
Current in Amps & 4.99 \\
\hline I.sc & 5 \\
V.oc & 18.13 \\
Solar cells & 30 \\
\hline
\end{tabular}

\subsection{The Boost DC/DC Converter}

A DC-DC converter is also known as a chopper or switching regulator fig as shown in below with PWM. It is simple, accurate and very easy to implement. If in duty cycle, the step change is large, then it has high tracking speed. Step change in duty cycle is small; it gives high accuracy result the average output is controlled by varying the conduction time $t$ of transistor $q$ and using the duty cycle of the copper. The converter use capacitor diodes and TRIAC as shown in below fig. 2.3.

DOI Number: https://doi.org/10.30780/IJTRS.V04.I07.001

pg. 2

www.ijtrs.com

www.ijtrs.org 


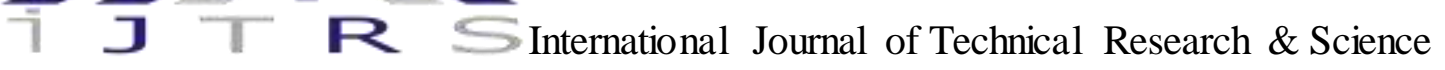

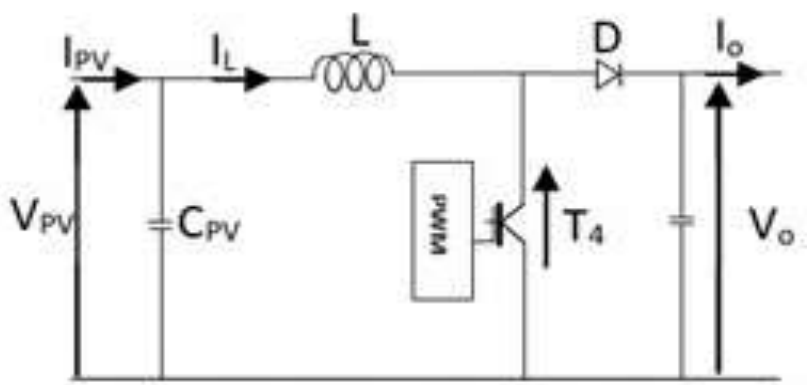

Fig. 2.3 Boost Power Converter

Below eqations for DC/DC converter:

$$
\begin{gathered}
L \frac{d i_{L}}{d t}=V_{p v}-V_{0}(1-u) \\
C_{p v} \frac{d V_{p v}}{d t}=i_{p v}-i_{L} \\
C_{o} \frac{d V_{o}}{d t}=-i_{o}-i_{L}(1-u)
\end{gathered}
$$

\subsection{Boost Backstepping Controller}

Below derived equation for backstepping controller Step1:

Based on input voltage derived

$$
\begin{gathered}
\varepsilon_{1}=V_{p v}-V_{\text {ref }} \\
\dot{\varepsilon_{1}}=V_{p v}-V_{\text {ref }}=\left[\frac{i_{p v}}{C_{p v}}-\frac{i_{L}}{C_{p v}}\right]
\end{gathered}
$$

Where $K_{1}>0$

$$
\begin{gathered}
\mathrm{V}_{1}=\frac{1}{2} \varepsilon_{1}^{2} \\
\dot{\mathrm{V}}_{1} \stackrel{\dot{=}}{=} \varepsilon_{1}\left[\left(\frac{\mathrm{i}_{\mathrm{pv}}}{\mathrm{C}_{\mathrm{pv}}}-\frac{\mathrm{i}_{\mathrm{L}}}{\mathrm{C}_{\mathrm{pv}}}\right)-\dot{\mathrm{V}}_{\mathrm{ref}}\right] \\
{\left[\left(\frac{\mathrm{i}_{\mathrm{pv}}}{\mathrm{C}_{\mathrm{pv}}}-\frac{\mathrm{i}_{\mathrm{L}}}{\mathrm{C}_{\mathrm{pv}}}\right)-\dot{\mathrm{V}}_{\mathrm{ref}}\right]=-\mathrm{K}_{1} \varepsilon_{1}}
\end{gathered}
$$

In equation $13 \mathrm{~K}$ is constant

$$
\begin{gathered}
\dot{\mathrm{V}}_{1}=-\mathrm{K}_{1} \varepsilon_{1}^{2}<0 \\
i_{L}=i_{p v}+K_{1} \varepsilon_{1} C_{p v}-C_{p v} \dot{V}_{r e f} \\
\propto_{1}=i_{d}=i_{L}=i_{p v}+K_{1} \varepsilon_{1} C_{p v}-C_{p v} \dot{V}_{r e f}
\end{gathered}
$$

Step2: $\varepsilon_{2}=i_{L}-\propto_{1}$

$$
\begin{gathered}
\dot{\varepsilon}_{2}=\frac{\mathrm{di}_{\mathrm{L}}}{\mathrm{dt}}-\dot{\alpha}_{1}=\frac{1}{\mathrm{~L}}\left(\mathrm{~V}_{\mathrm{pv}}-\mathrm{V}_{\mathrm{o}}(1-\mathrm{u})\right)-\dot{\alpha}_{1} \\
\dot{\varepsilon}_{2}=\left[\frac{i_{p v}}{c_{p v}}-\frac{\varepsilon_{2}+\alpha_{1}}{C_{p v}}\right]-\dot{V}_{r e f} \\
: \varepsilon_{1}^{\prime}=-K_{1} \varepsilon_{1}-\frac{\varepsilon_{2}}{C_{p v}}
\end{gathered}
$$

We are fallows the step by step the we expected the exact output

$$
\begin{gathered}
\dot{V}_{1}=-K_{1} \varepsilon_{1}^{2}-\frac{\varepsilon_{1} \varepsilon_{2}}{C_{p v}} \\
\dot{\alpha_{1}}=l_{p v}+C_{p v} K_{1} \dot{\varepsilon}_{1}-C_{p v} V_{r e f}^{*} \\
V_{2}=V_{1}+\frac{1}{2} \varepsilon_{2}^{2} \\
\dot{V}_{2}=\dot{V}_{1}+\varepsilon_{2} \dot{\varepsilon}_{2} \\
\dot{V}_{2}=K_{1} \varepsilon_{1}^{2}+\varepsilon_{2}\left[-\frac{\varepsilon_{1}}{C_{p v}}+\frac{V_{p v}}{L}-\frac{1-u}{L} V_{0}-\dot{\alpha}_{1}\right]
\end{gathered}
$$

The negative is:

$$
u=1-\frac{L}{V_{0}}\left[-\frac{\varepsilon_{1}}{C_{p v}}+\frac{V_{p v}}{L}+K_{2} \varepsilon_{2}-\dot{\alpha_{1}}\right]
$$

The above choice provides:

$$
\dot{V}_{2}=-K_{1} \varepsilon_{1}^{2}+K_{2} \varepsilon_{2}^{2}
$$

DOI Number: https://doi.org/10.30780/IJTRS.V04.I07.001

pg. 3

www.ijtrs.com

www.ijtrs.org 


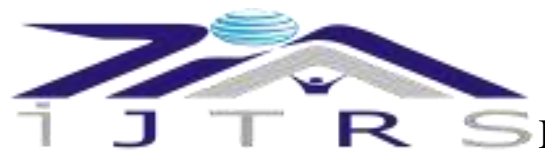

\section{International Journal of Technical Research \& Science}

By using above equation we are equating the block from back stepping controller. The output expected the DC voltage and current shows

Solar module is a series or parallel configuration of PV cells. Series configuration of cells is used to generate power at a higher potential with current remaining unchanged, whereas the parallel configuration will generate higher current while the potential remains unchanged

$>$ The PMDC Parameter for given for values below for boost converter is:

clear all;

close all;

clc;

$\% \%$ PMDC parameters

$\mathrm{K} 1=500$;

$\mathrm{K} 2=1000$;

$\mathrm{Cm}=(6700 \mathrm{e}-6)$;

$\mathrm{Ci}=(500 \mathrm{e}-6)$;

$\mathrm{L}=4 \mathrm{e}-3$;

$\mathrm{R}=50$;

\subsection{Reference Voltage}

It is a technique. It is simple, accurate and very easy to implement. If in duty cycle, the step changes is large, then it has high tracking speed. Step change in duty cycle is small, it gives high accuracy result

The voltage at that PV module will manufacture most power is termed 'maximum power point' It is simple, accurate and very easy to implement. If in duty cycle, the step changes is large, then it has high tracking speed. Step change in duty cycle is small; it gives high accuracy result (or peak power voltage). The solar cell's output potential varies quite a bit with respect to the solar radiation, ambient temperature and solar cell temperature etc.

In $\mathrm{V}$ is reference is the input voltage is designed from the $\mathrm{p}$ \&o flowchart with using pv voltage is starting steps to the finally we are using $\mathrm{P}(\mathrm{K}-1)=\mathrm{P}(\mathrm{K})$.

Solar module is a series or parallel configuration of PV cells. Series configuration of cells is used to generate power at a higher potential with current remaining unchanged, whereas the parallel configuration will generate higher current while the potential remains unchanged

It is simple, accurate and very easy to implement. If in duty cycle, the step changes is large, then it has high tracking speed. Step change in duty cycle is small, it gives high accuracy result.

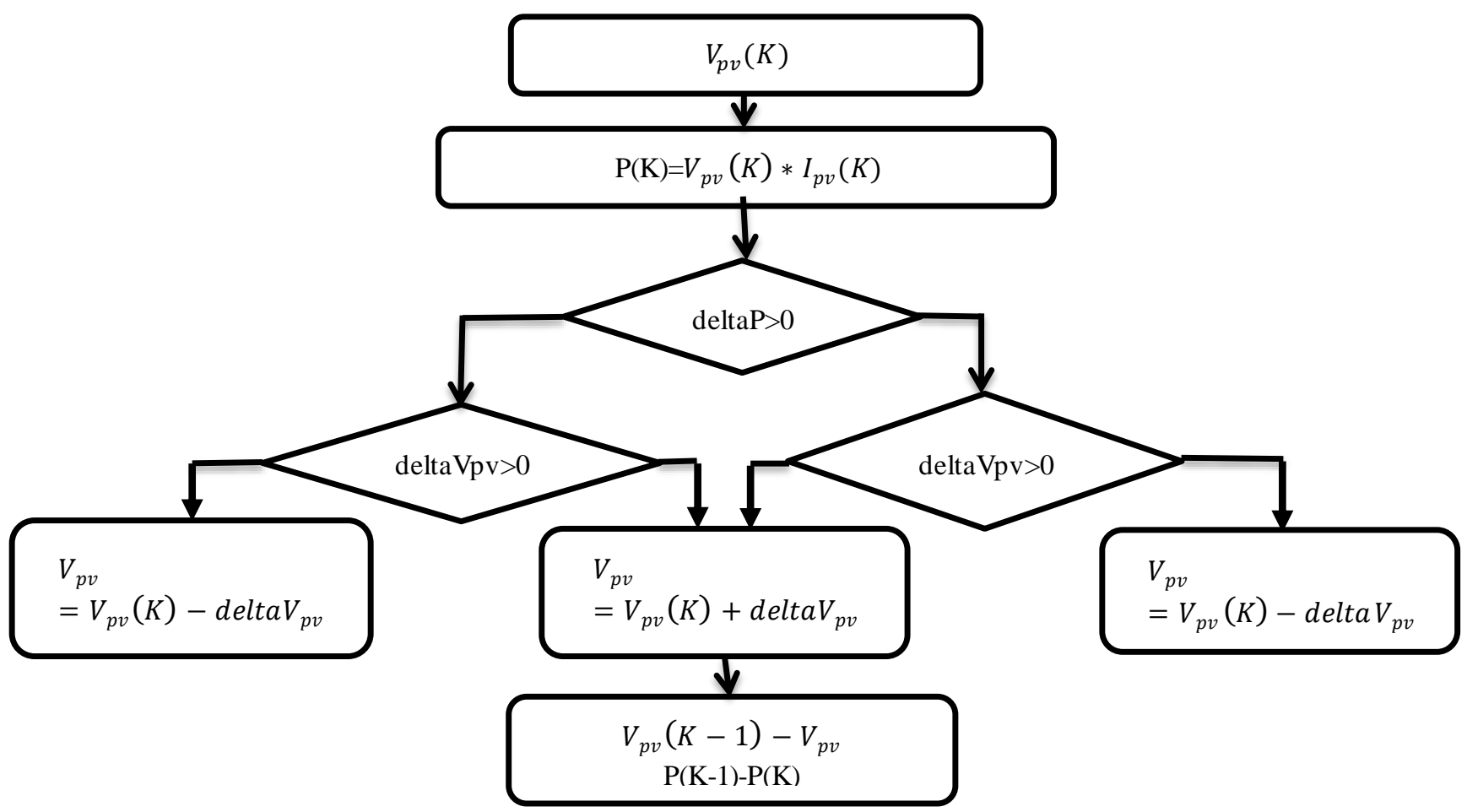

Fig. 2.4 P\&O Flowchart

DOI Number: https://doi.org/10.30780/IJTRS.V04.I07.001

pg. 4

www.ijtrs.com

www.ijtrs.org 


\section{SIMULATION RESULTS}

Based on the results above, the backstepping controller is able to sustain the output voltage of the photovoltaic generator at optimum point and the maximum power point is always achieved with low losses. It is simple, accurate and very easy to implement. If in duty cycle, the step change is large, then it has high tracking speed. Step change in duty cycle is small, it gives high accuracy result. Solar module is a series or parallel configuration of PV cells. Series configuration of cells is used to generate power at a higher potential with current remaining unchanged, whereas the parallel configuration will generate higher current while the potential remains unchanged.

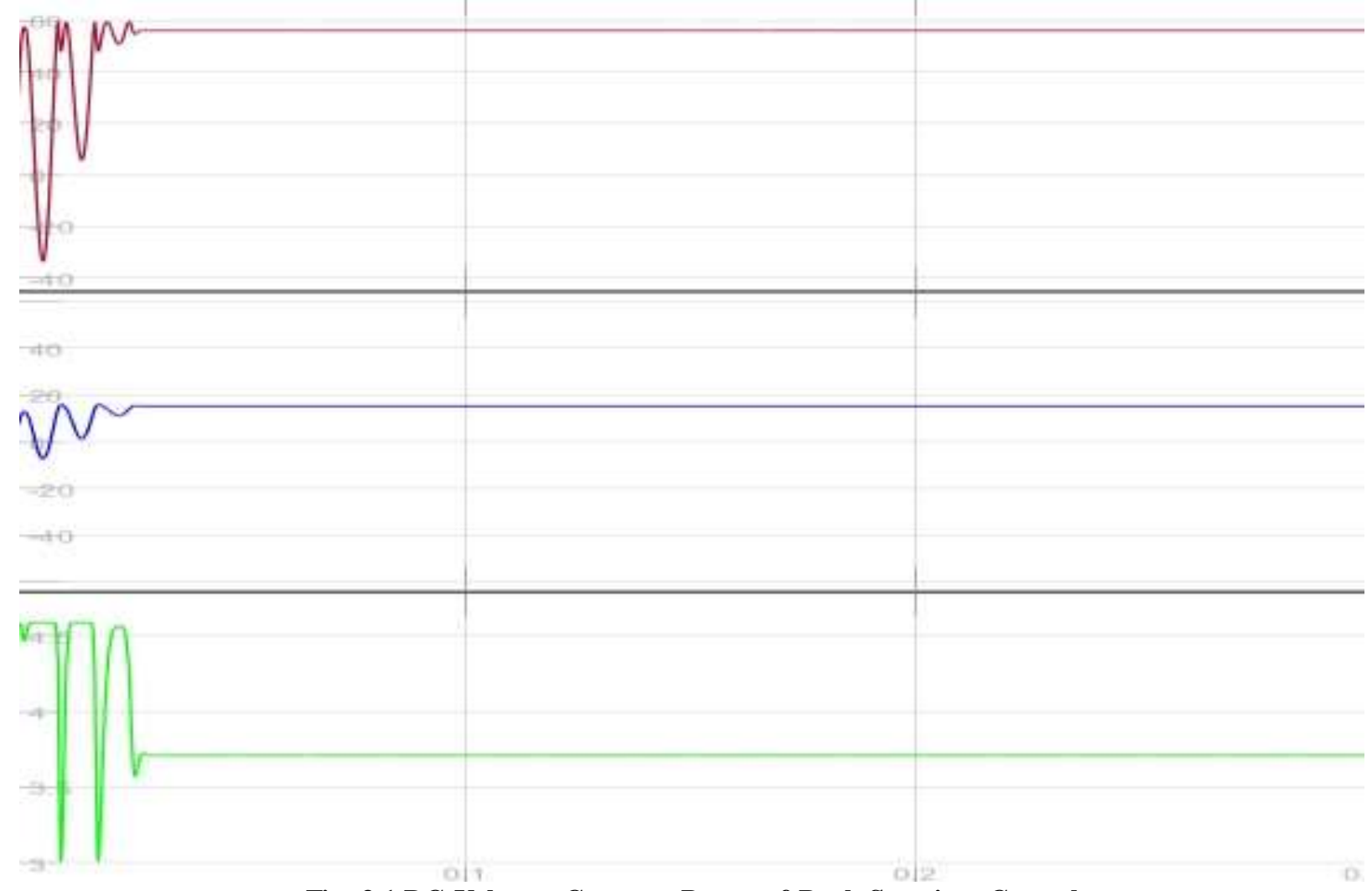

Fig. 3.1 DC Voltage, Current, Power of Back Stepping Control
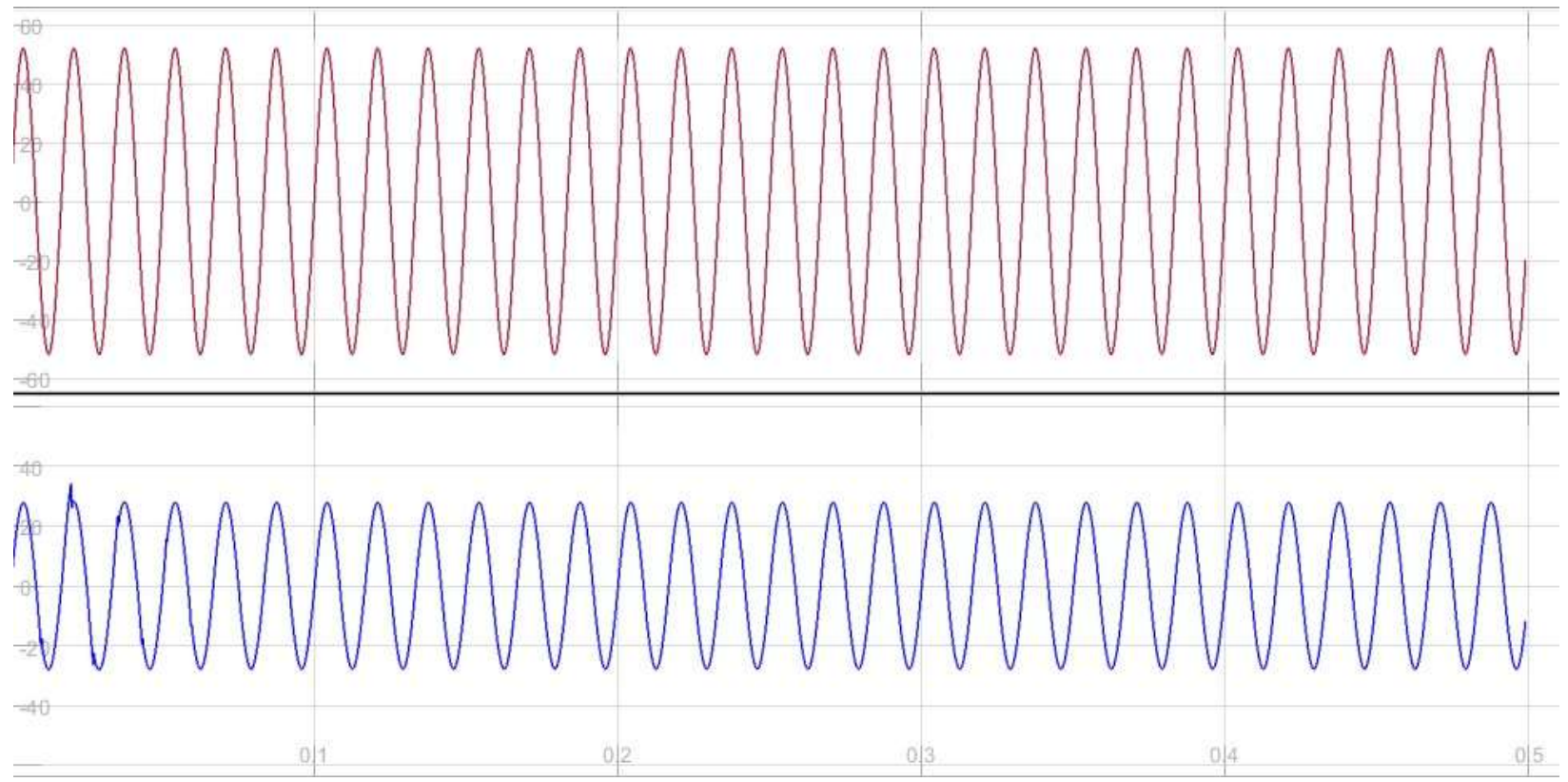

Fig. 3.2 AC Grid Voltage, Current

DOI Number: https://doi.org/10.30780/IJTRS.V04.I07.001

pg. 5

Www.ijtrs.com

www.ijtrs.org

Paper Id: IJTRS-V4-I5-030

Volume IV Issue VII, July 2019

@,2017, IJTRS All Right Reserved 

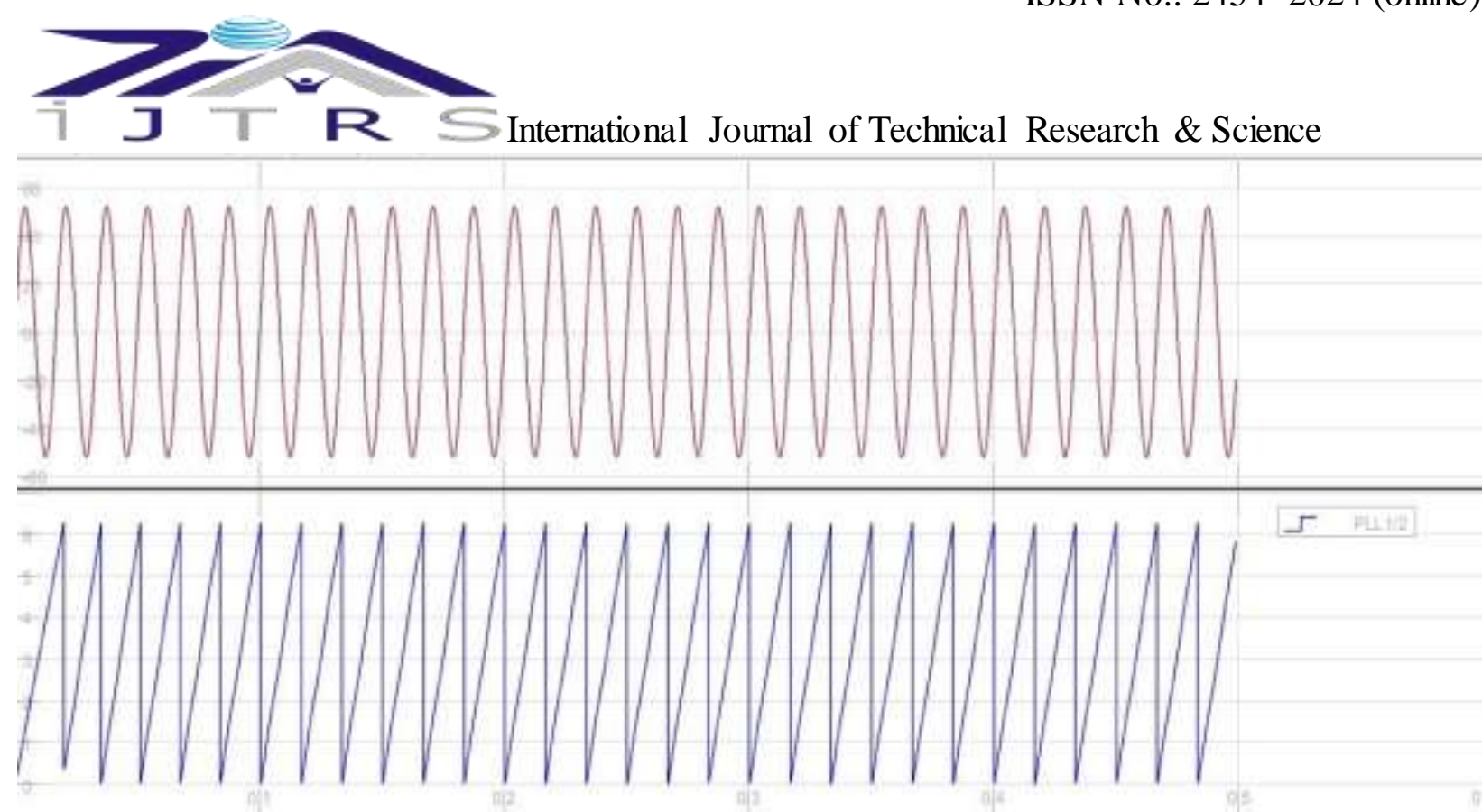

Fig. 3.3 AC Inverter Grid, PLL

\section{1แس}

\section{IIIIIIIIIIIIIIIIIIIIIIIIII}

\section{IIIIIIIIIIIIIIIIIIIIIIIIIIIII}

\section{IIIIIIIIIIIIIIIIIIIIIIIIIIII}

Fig. 3.4 Phases in AC

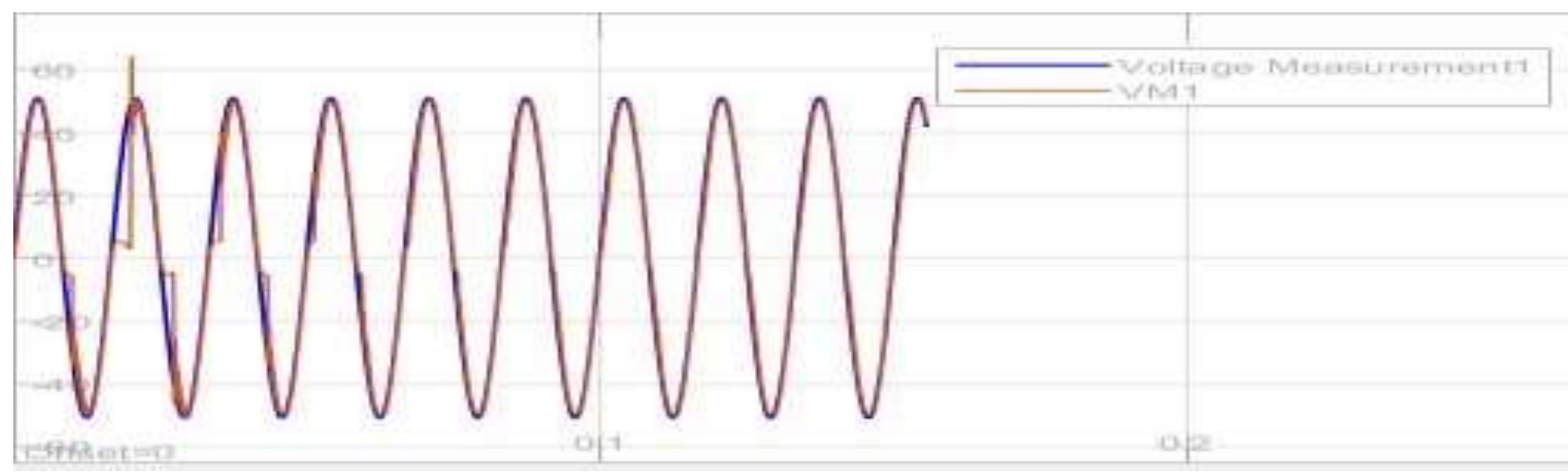

(a)

DOI Number: https://doi.org/10.30780/IJTRS.V04.107.001

pg. 6

www.jitrs.com

www.ijtrs.org

Paper Id: IJTRS-V4-I5-030

Volume IV Issue VII, July 2019 


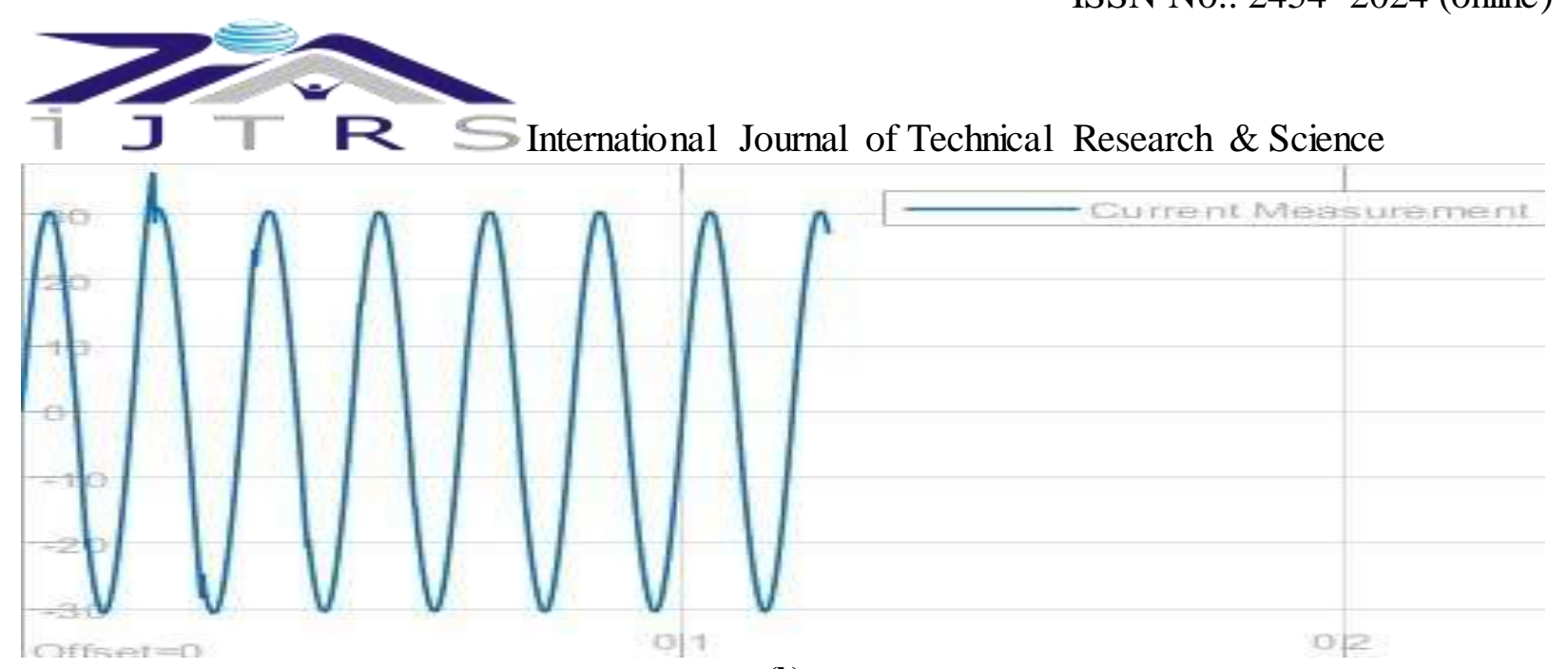

(b)

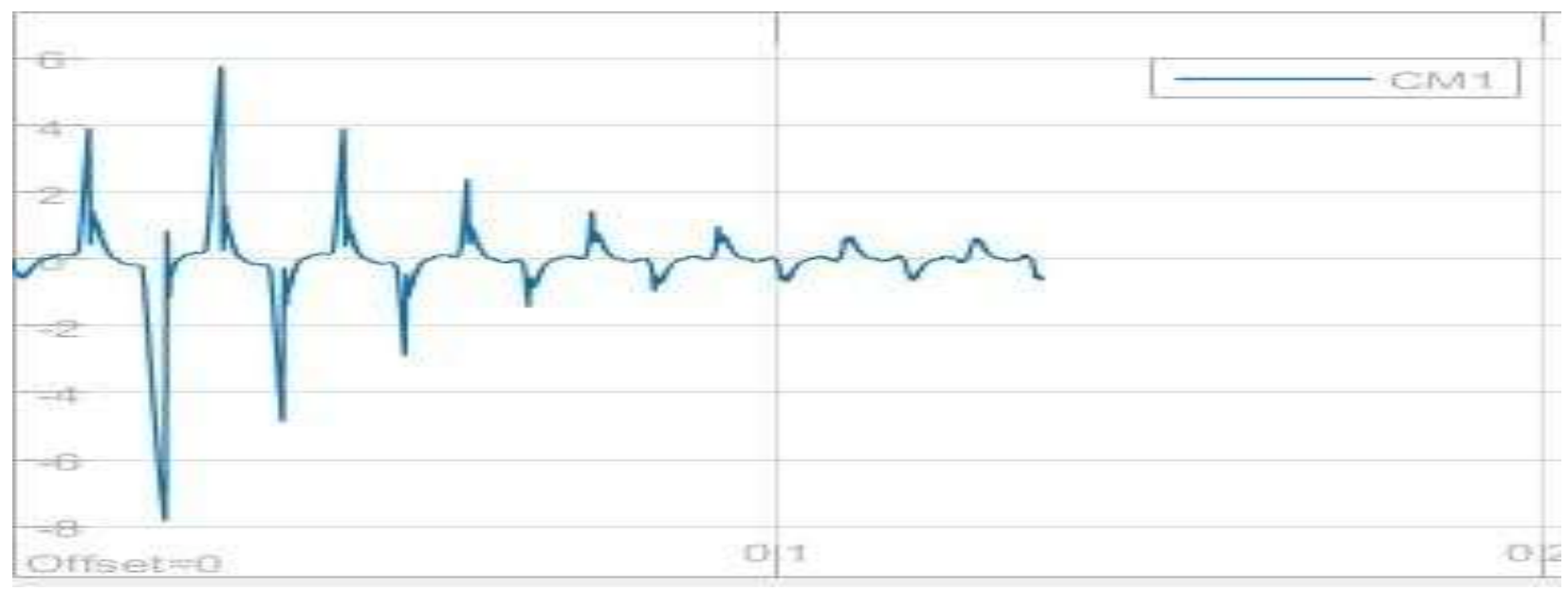

(c)

Fig. 3.5 Simulation Results: (a) AC grid Voltage and Inverse Voltage (b) Grid Current (c) Inverse Current

It is simple, accurate and very easy to implement. If in duty cycle, the step change is large, then it has high tracking speed. Step change in duty cycle is small, it gives high accuracy result.

\section{CONCLUSION}

The backstepping controller is to track the maximum power point of a photovoltaic system is designed with grid connected inverter. The grid connected inverter maximum output power is to be reach near $52 \mathrm{~V}$ and also based on nonlinear controller is used to applied to a boost convert to achieve the photovoltaic array output voltage, to check the instead of using backsteping controller PI, PID controller and artificial neuronal network is a good choice when a high efficiency MPP tracking is needed but this controller suffer from loss of robustness against ageing of PV modules. The reference voltage is to be obtained with the help of the perturb and observe. It is simple, accurate and very easy to implement. If in duty cycle, the step change is large, then it has high tracking speed. Step change in duty cycle is small, it gives high accuracy result.

\section{ACKNOWLEDGEMENT}

The authors thank the authorities of Nitte Meenakshi Institute of Technology, Yelahanka. The facilities provided and the motivation by the Head of Department, Dr.V.Ranganathan is gratefully acknowledged.

\section{REFERENCES}

[1] Tasi-Fu Wu; Yu-Kai Chen, "Modeling PWM DC/DC Converters out of Basic Converter Units", IEEE Transactions on Power Electronics, vol. 13, no. 5, pp. 870-881, 1998.W.-K. Chen, Linear Networks and Systems.Belmont, CA: Wadsworth, 1993, pp. 123-135.

[2] N. Kasa, T. Iida and G. Majumdar, "Robust control for maximum power point tracking in photovoltaic power systems," Proc. Power Conv. Conf., vol. 2, no. 1, pp. 827-832, Apr. 2002.

[3] Elgendy, M. A.; Zahawi, B.; Atkinson, D. J., "Evaluation of the P\&O MPPT Algorithm for Implementation Techniques", 6th IET International Conference on Power Electronics, Machines and Drives (PEMD), pp.1-6. 
J I R International Journal of Technical Research \& Science

[4] M. I. Arteaga Orozco, J. R. Vázquez, P. Salmerón, "MPP Tracker of a PV System using Sliding Mode Control with Minimum Transient Response", International Review on Modelling and Simulations (I.RE.MO.S.), December 2010.

[5] M.Kermadi, E.Brekouk," Artificial intelligence-based MPPT controllers for Photovoltaic systems: Comparative study", Renewable and Sustainable Energy Reviews, vol.69, pp. 369-386, February2016.

[6] Youping Zhang, Barıs, Fidan, "Backstepping Control of nonlinear Time Varying Systems with Known and Unknown Parameters",

[7] IEEE Transactions on Automatic Control, vol. 48, no. 11, November 2003.

[8] El Fadil, H.; Girt, F., "Backstepping Based Control of PWM DC-DC Boost Power Converters", Symposium on Industrial Electronics, ISIE 2007, pp. 395-400, 2007.

[9] Fan Liping; Yu Yazhou; Boshnakov, K., "Backstepping Based Terminal Sliding Mode Control by using DCDC Convertor",

[10].Walker, Geoff R. "Evaluating MPPT converter topologies using the MATLAB PV model" Australasian Universities Power Engineering Conference, AUPEC ‘00,Brisbane, 2000

[11] J. A. Gow, “Development of thepv array model for usingthe PE simulation studies," IEE Proceedings on the Electric Power Applications, vol. 146, no. 2, pp. 193-200, March 1999.

[12] Paraskevadaki, E.V.; Papathanassiou, S.A., "Evaluation of MPP Voltage and Power of me-Si PV Modules into Partial Shading Conditions", IEEE Transactions on Energy Conversion, vol. 26, no. 3, pp. 923-932, 2011.

[13] Ishaque K, Salam Z. A review of maximum power point tracking techniques of PV system for uniform insolation, partial shading condition. Renew Sustain Energy Rev 2013;19(0):475-88.

[14] Tekeshwar Prasad Sahu, T. v. Dixit, "Modelling andthe Analysis of Perturb and Observe and Incremental Conductance MPPT Algorithm for PV Array Using Cuk Converter”, IEEE Student's Conference on Electrical, Electronics and Computer Science, 2014, pp. 1-6.

[15] Guo, X.Q.; Wu, W.Y.; Gu, H.R. Phase locked loop and synchronization methods for grid-interfaced converters: review. PrzegladElektrotchniczny (Electr. Rev.) 2011, 87, 182-187.

[16] Hsieh, G.C.; Hung, J.C. Phase-locked of loop techniques-A survey. IEEE Trans. Ind. Electron. 1996, 43, 609615. [CrossRef] 